\title{
Hibridação intersensorial, intertextual-semiótica e interformativa: trans-hibridações
}

Agnus Valente

\section{Resumo:}

Este artigo apresenta minhas contribuições teóricas para os estudos dos Métodos Heurísticos da Criação: a formulação dos conceitos de "hibridação intersensorial", "hibridação intertextual-semiótica" e "hibridação interformativa". A hibridação intersensorial apóia-se na noção dos "meios produtivos como extensão do homem" (McLuhan); a hibridação intertextual-semiótica funda-se na acepção do termo "texto" expandido do código verbal ao visual e a outros "sistemas sígnicos" (Kristeva, Bense, Peirce), embasada numa "intertextualidade poética ou crítica" (Perrone-Moysés) e na "tradução intersemiótica" (Jakobson, Plaza); e a hibridação interformativa associa o conceito de "formatividade" (Pareyson) à produção (co-autorias, influências e/ou linhagens artísticas) e à recepção (obras interativas). A abrangência desses conceitos nos permite reconhecê-los em diversos campos da criação humana, de acordo com a "predominância" (Jakobson) com que comparecem nos processos de trans-hibridação.

\section{Palavras Chave:}

Hibridação intersensorial intertextual-semiótica e interformativa, hibridismo, trans-hibridação.

\begin{abstract}
:
This article presents my theoretical contributions to the studies of the Heuristic Methods of Creation - the innovative concepts of "intersensorial hybridation", "intertextual-semiotic hybridation" and "interformative hybridation". The intersensorial hybridation is founded on the productive "media as extension of man" (McLuhan); the intertextual-semiotic hybridation employes the meaning of the term "text" expanded from the verbal to the visual codes and other "signs systems" (Kristeva, Bense, Peirce), based on "poetic or critical intertextuality" (Perrone-Moysés) and on "intersemiotic translation" (Jakobson, Plaza); and the interformative hybridation links the concept of "formativity" (Pareyson) to the production (co-authorial creations and artistic influences) and to the reception (interactive artworks). Their amplitude allows us to recognize them in many fields of human creation according to the "predominant" (Jakobson) occurrence in the process of trans-hybridation.
\end{abstract}

\section{Keywords:}

Intersensorial intertextual-semiotic and interformative hybridation, hybridism, trans-hybridation. 


\section{Apresentação}

“Um homem distinto é um homem misturado”. (Montaigne)

A referência principal deste texto é minha tese de Doutorado [VALENTE,2008], que investiga os processos de hibridação num aprofundamento das reflexões advindas de minha dissertação de Mestrado PARABOLA-IMAGO: Transmutações Criativas entre o Verbal e o Visual [VALENTE,2002]. O corpus de obras resultante dessas "transmutações" revelou uma praxis artística que ultrapassou o binômio palavra/imagem inicialmente proposto. As operações ali engendradas colocaram em circulação não apenas a duplicidade dos códigos verbal e visual, mas também os sistemas artísticos envolvidos Literatura e Artes Visuais. Para além desse hibridismo de sistemas significantes, a pesquisa criativa abarcou os meios de produção industrial e tecnológico-digital, bem como agregou Poéticas Digitais, Poesia Concreta, Intertextualidade, Obra Aberta, Tradução Intersemiótica, Interatividade etc — à luz das referências e influências poéticas de meus mestres da Literatura e das Artes Visuais (Ibid. :176).

No espírito de perscrutar essas múltiplas modalidades de hibridação em minha poética pessoal, como artista híbrido, coloquei em perspectiva o processo criativo do projeto artístico ÚTERO portanto COSMOS de minha autoria, para desvendar os processos híbridos que lhes deram forma, analisá-los e conceituá-los.

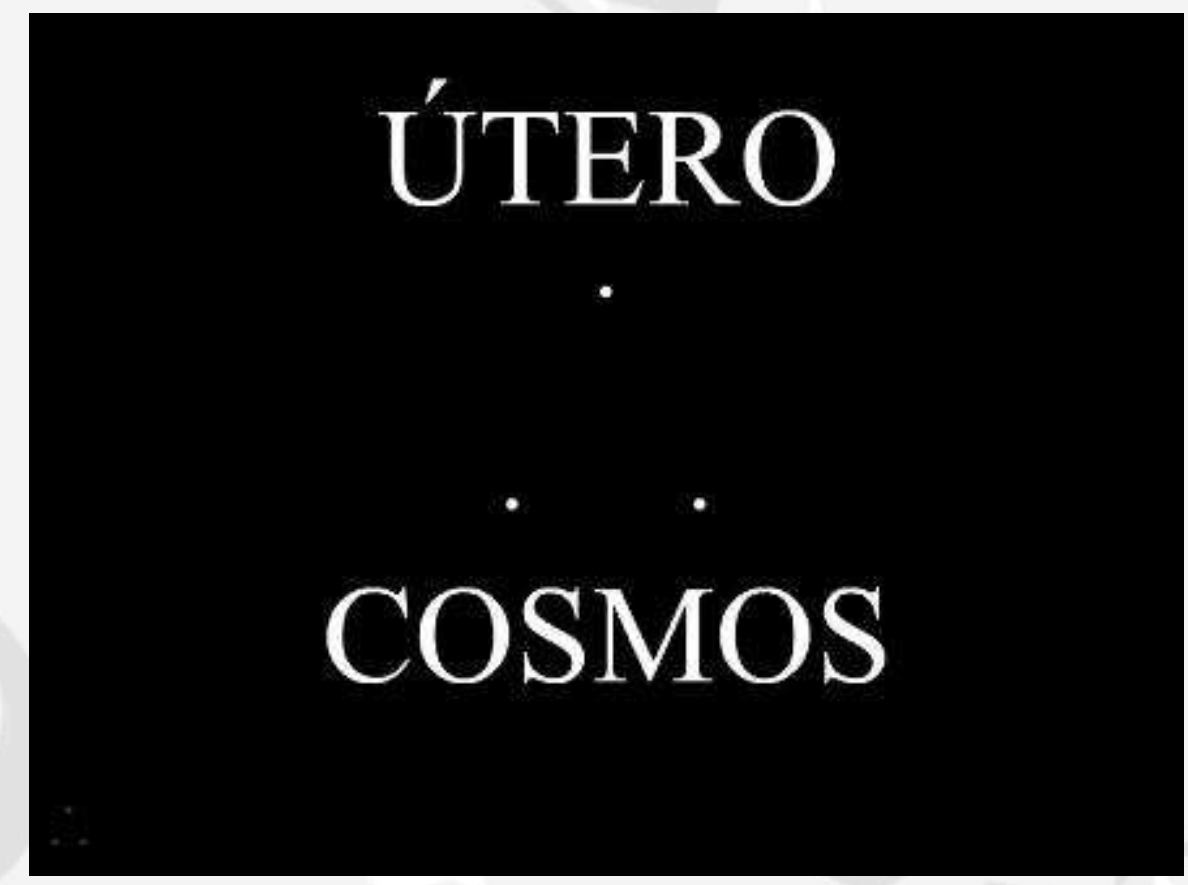

\section{$\underline{\text { ÚTERO portanto COSMOS }}$}

aGNuS VaLeNTe

copyright 2002-2009

Este texto de metalinguagem focaliza seu objeto de estudo nessa praxis, na qual hibridismo não é apenas 
tema ou assunto. Trata-se de uma reflexão em consonância com as operações híbridas efetivamente articuladas no cerne do processo de criação em meio digital, na matriz da Poesia Concreta e Visual em hibridações com diferentes sistemas significantes, e a partir de minha poética híbrida com minhas referências, afinidades e filiações artísticas pessoais. Essa investigação culminou em contribuições teóricas para os estudos dos Métodos Heurísticos da Criação (1) com minhas formulações dos conceitos de "hibridação intersensorial", "hibridação intertextual-semiótica" e "hibridação interformativa".

Nesse espírito, o relato dessa pesquisa a posteriori é apresentado na expectativa de contribuir para a compreensão dessas operações, não somente na circunscrição de minha produção pessoal mas também, por seu caráter geral e abrangente, no âmbito da produção artística contemporânea, no campo do hibridismo em artes.

\section{Introdução}

"Operations Research programs the hybrid principle as a technique of creative discovery" (Marshall McLuhan)

O termo "hibridações" é aqui compreendido, proposto e empregado como procedimento poético, partindo da premissa em epígrafe de um "princípio híbrido como uma técnica de descoberta criativa" [MCLUHAN, c1964,1994:55], princípio metodológico que considero fértil particularmente no contexto da arte digital.

A ação de hibridar meios produtivos como metodologia de criação pode ser intencional ou casual. Em ambos os casos, contudo, é preciso lembrar que os meios são "agentes produtores de acontecimentos, mas não agentes produtores de consciência", já que na relação homem/máquina a consciência é uma prerrogativa humana. Eu diria que, nos processos híbridos, a fusão ou a fissão de diferentes agentes produz o fato mas não produz o pathos; oferece, antes, "uma oportunidade especialmente favorável para a observação de seus componentes e propriedades estruturais" [Id.,1969:67], cabendo ao criador a abordagem reflexiva inteligível ou sensível sobre os fenômenos ocorridos, bem como a atribuição de sentidos e significações a partir de suas interpretações para os efeitos e para as imagens significantes deflagradas por essas misturas ou encontros. Nesse ponto, sugiro a expansão do termo "agentes", que aqui representa os meios produtivos, de modo a incluir também os sistemas artísticos e as poéticas históricas ou pessoais.

Em minha abordagem sobre esses fenômenos de hibridação que formulei, enfatizo a importância das interrelações desses processos, nos quais a hibridação intersensorial, intertextual-semiótica e interformativa se mesclam ou se permeiam ininterruptamente. Interessa-me investigar os efeitos de uma hibridação sobre as outras e suas interpenetrações, lembrando que a distribuição das operações entre três categorias de processos de hibridação atende a uma necessidade estritamente analítica, não cabendo supor monopólios, mas sim a ocorrência integrada das diferentes hibridações. Nesse sentido, recomenda-se no estudo desses processos uma especial atenção para discernir a predominância (2) de uma hibridação, sem contudo descartar a "participação adicional" das demais hibridações em curso.

\section{Hibridação intersensorial}

“O híbrido, ou encontro de dois meios, constitui um momento de verdade e revelação, do qual nasce a forma nova". (Marshall McLuhan)

O meio produtivo tecnológico digital renovou os modos de criação, geração, transmissão, conservação e percepção das imagens. Com seu caráter cumulativo, investe numa vertente conservadora e também 
inovadora [PLAZA,1991:ix-x]. A vertente conservadora visa à preservação do passado, fundada no conceito de Museu Imaginário de André Malraux, através da recodificação do repertório dos meios de produção tradicionais (artesanal e industrial), reorganizando-o no novo meio. A vertente inovadora, fundada na constituição de uma nova linguagem, promove uma transformação da criação audiovisual e cinética, suscitando novos imaginários e discursos icônicos, confluindo para as 'hibridações multimídia e hipermídia' [Id.,2000] que são características do meio digital.

O diálogo entre múltiplos meios em ambiente tecnológico-digital desenvolve-se de modo amplo, no qual "intervêm outras modalidades além da linguagem, a exemplo das modalidades visuais, sonoras, gestuais, e até mesmo táteis" [COUCHOT in LEÃO,2002:104] próprias de cada meio contemporizado no processo de criação digital. Os meios correspondem a aspectos sensoriais ligados aos sentidos físicos humanos de modo que, na medida em que se interrelacionam, "os meios, como extensões de nossos sentidos, estabelecem novos índices relacionais, não apenas entre os nossos sentidos particulares, como também entre si" [MCLUHAN,1969:72], produzindo um "intercurso dos sentidos" [PLAZA, 1987:45-69] - como vemos na matriz híbrida da Poesia Concreta que hoje, em simbiose com o meio produtivo digital, atualiza aquelas experimentações intersensoriais propostas pelos poetas concretos e sugeridas no neologismo "verbivocovisual" (3).

Esse intercurso de sentidos promovido pela hibridação de meios implementa o que concebi e denominei como hibridação intersensorial. Essa operação ocorre na medida em que os recursos dos meios empregados envolvam efetivamente mais de um dos sentidos humanos - visão, audição, tato etc. Lembremos as experiências recentes para a virtualização e atualização do olfato em meio digital, visando à articulação conjunta de todos os sentidos em um mesmo ambiente representacional.

Simultaneamente à contemporização de múltiplos meios, o digital promove também cruzamentos de sistemas. Isto porquê a tecnologia atualiza as imagens de meios artesanais e industriais; e estes, por sua vez, carreiam para o novo ambiente os seus sistemas de representação - desenho e pintura (artesanal); artes gráficas, fotografia e cinema (industrial). Ou seja, nesse contexto, intervém uma outra modalidade: a linguagem que, através dos códigos visuais, verbais e sonoros daqueles sentidos mencionados anteriormente, introduz os seus correspondentes sistemas de signos. Assim, fundada naqueles "efeitos do tratamento numérico da informação que se infiltra no cerne das operações" [COUCHT in LEÃO,2002:104] em ambiente digital, e que recodifica os demais meios e códigos, a hibridação de meios também configura um campo propício para subseqüentes misturas - e envolve, extensivamente, elementos de hibridações de sistemas artísticos.

\section{Hibridação intertextual-semiótica}

“Uma das causas mais comuns de ruptura em qualquer sistema é o cruzamento com outro sistema”. (Marshall McLuhan)

A hibridação de sistemas mobiliza diferentes sistemas além da Arte, revelando uma reflexão interdisciplinar que absorve outras áreas do conhecimento como Filosofia, Ciência, Astronomia, Arquitetura, Design etc. investindo em aproximações e licenças poéticas numa espécie de encantamento pelas sugestivas e potentes imagens de suas formulações.

Revela-se, nestes casos, uma operação similar ao "método de transferência" de Abraham Moles [1981:8485]. O transferir de um pensamento de seu campo do saber para um outro é uma das mais frutíferas operações tanto para a criação como para a pesquisa. Esse método fundamenta-se na analogia que comparece, mais ou menos conscientemente, nos deslocamentos de um campo de conhecimento para outro domínio, tanto do ponto de vista racional como intuitivo. Privilegiando as associações que ocorrem 
por similaridade/semelhança, promove conexões entre um ou mais caracteres qualitativos entre os sistemas envolvidos.

A hibridação de sistemas consiste numa hibridez de "textos" ou numa hibridez de "sistemas de signos", onde o termo "texto" (4) é considerado em sentido ampliado para além do verbal e atinge as artes e linguagens visuais [BENSE,1975:179] e o amplo "sistema de signos" (5) passa a focalizar, inclusivamente, o texto verbal; do mesmo modo, o caráter restritivo do termo "intertextualidade", antes confinado às linguagens verbais, é neutralizado, passando a também referir, mais amplamente, às linguagens não-verbais [KRISTEVA, 1974:60].

Exemplarmente, a dissolução de fronteiras entre Poesia e Artes Visuais promovida pela Poesia Concreta proporcionou "um encontro esclarecedor da linguagem impressa com a imagem pictórica" [ARNHEIM,1989:95]. O poema concreto "realiza a proeza de trazer" - e eu diria hibridar - "as virtualidades da comunicação não-verbal" da imagem pictórica, como seu traço alusivo, "sem abdicar de qualquer das peculiaridades da palavra" [CAMPOS,1975:81-82], como seu lastro de conteúdo e seu traço legível de texto impresso, que é ao mesmo tempo uma imagem tipográfica e uma "imagem acústica" (6). Essa expansão da poesia para outros campos revela a importância das isomorfias entre os diversos sistemas artísticos para articular a problemática espaço/tempo (movimento) que são comuns tanto à literatura quanto às artes visuais, à arquitetura, teatro e à música eletrônica [PIGNATARI,1975:40].

Nessa perspectiva, concebo nas operações criativas da Poesia Concreta respectivamente uma hibridação de cunho intertextual, como criação entre-textos se considerarmos aqui aquela acepção ampliada de texto verbal e não-verbal, e uma hibridação de cunho intersemiótico, como criação entre sistemas sígnicos, semióticos - conceitos extensíveis a todas as criações que mesclam diferentes sistemas artísticos, como por exemplo Animação, Vídeo, Cinema, Teatro, Ópera etc incluindo também os sistemas verbais.

Os conceitos de Intertextualidade e Tradução Intersemiótica enquanto promotores de hibridação, assim apostos, aparentemente podem depor uma redundância de termos. Contudo, são emblematicamente representativos da interpenetração das operações de hibridação na medida em que ambos romperam o perímetro de seus sistemas. A noção de intertextualidade ligada ao texto verbal e a noção de intersemiótica como pertencente a uma ordem não interlingual nem intralingual mas, digamos, intersígnica, expandiram-se em suas abrangências, promoveram uma dissolução de fronteiras, empreendendo um movimento um em direção ao campo do outro - conceitos ideais para a compreensão das operações de hibridação na medida em que atuam conjuntamente. Partindo da tipologia das traduções de Jakobson, que as define em três categorias distintas, eu visualizo um operar híbrido que, inexistente na primeira categoria, gradualmente surge na segunda até imperar na tradução inter-semiótica (7), uma vez que a tradução intralingual opera uma reformulação de signos verbais em signos verbais da mesma língua ou idioma; a tradução interlingual, que é a tradução propriamente dita, traduz signos verbais em signos verbais de outra língua ou idioma; e a tradução inter-semiótica elabora uma interpretação de signos verbais em signos não-verbais e envolve necessariamente diferentes sistemas sígnicos [JAKOBSON,1988:64-65].

A conjunção dos conceitos de intertextualidade e intersemiótica levou-me à formulação da hibridação de sistemas como uma hibridação intertextual-semiótica (8) sem prescindir uma da outra, considerando-se o quanto estão imbricadas. Desse modo, mantenho o conceito o mais amplo possível, distante de polêmicas e conflitos interdisciplinares sobre a noção de texto verbal ou não-verbal dos mais ortodoxos. Contudo, é possível aferir uma predominância nas operações híbridas entre sistemas se considerarmos - se for necessário fazê-lo - o quanto o fenômeno operado tende a um produto final textual ou semiótico. 


\section{Hibridação Intertextual}

Além das hibridações imersas no próprio processo criativo, um procedimento a ser sublinhado é o ato de inserir uma obra pré-existente num programa artístico, numa clara intertextualidade como modalidade de hibridação. Trata-se, num primeiro momento, de uma operação de transposição que visualizo como um gesto intertextual que elege, pinça, traz e incorpora no texto poético uma obra na qual se reconhecem possibilidades de diálogos, contrapontos ou afinidades artísticas.

Na medida em que esse gesto intertextual é encarado como uma operação de reflexão ou de criação, essa hibridação pode adquirir nuances de uma espécie de "intertextualidade crítica" ou então de uma "intertextualidade poética" [PERRONE-MOYSÉS,1979:209-230]. Instaura-se um campo híbrido pendular entre uma ação crítica com licenças poéticas e uma ação poética com reflexões críticas, que conjugam simultaneamente as funções poética e metalinguística da Linguagem (9).

Se, de um lado, a ausência de fronteiras conduziria a ação crítica inteligível a uma expressão em vias de tornar-se poética; de outro, a ação poética elaboraria uma reflexão sensível em vias de tornar-se crítica transitando ambas de uma hibridação de sistemas a uma hibridação de poéticas.

\section{Hibridação Intersemiótica}

A Tradução Intersemiótica, em contrapartida, é uma operação que, mesmo operando entre os meios produtivos, incorpora uma hibridação de poéticas e de sistemas na medida em que "pensa as diversas formas da arte" [PLAZA,1987:209], revelando um traduzir que se efetiva entre diferentes sistemas semióticos, como Poesia Concreta, Fotografia, Cinema, Artes Visuais e Gráficas etc, promovendo transferências entre formas e autorias.

As traduções intersemióticas produzem hibridações conforme a tipologia da tradução seja simbólica, indicial ou icônica [PLAZA,1987:89-93]. Na tradução intersemiótica simbólica, temos uma transcodificação, na qual as poéticas do tradutor e autor são apartadas no ato da operação, imperando regras coercitivas e pré-determinadas pelos códigos dos meios transductores (a nota formativa do tradutor comparece na escolha do código); na tradução indicial temos uma transposição na qual prevalece ou o sistema ou a formatividade do autor original, que demanda do tradutor um mirar-se na ou um absorver o outro, numa tradução de caráter predominantemente paradigmático - o tradutor "imita" o modo do autor; e, na tradução icônica, temos uma transcriação na qual a interformatividade se revela na predominância do tradutor na obra, na medida em que este imprime sua própria visão, leitura, releitura, julgamento e interpretação sobre o original, a esta remetendo-se em alguns aspectos qualitativos, mas transformando significantemente o produto final.

A Tradução Intersemiótica, em ações de Intertextualidade, absorve também características da modalidade de hibridações intertextuais. Neste contexto, retomo o termo "transposição", que é o denominador comum entre elas. Na Intertextualidade, "transposição" é um termo-substituto para expandir o conceito de intertextualidade para as linguagens não-verbais (10), que designa a transferência de um ou mais sistemas em outro, tendo como pressuposto a transformação do original numa forma sempre correspondente - isto é, sua tradução. Na tipologia da Tradução Intersemiótica, o termo "transposição" (11) corresponde à operação de "tradução indicial", na qual o original é apropriado no todo ou em parte e "transladado" (12) para outro contexto, sendo então transformado qualitativamente sem, contudo, perder contato e continuidade entre original e tradução (haja vista que se mantêm equivalências transitivas entre suas estruturas).

A Tradução Intersemiótica, refletindo sobre as diferentes formas da arte, caracteriza a atitude tradutora 
como um pensar, um inteligir, um fazer que insere "a atividade crítico-metalinguística" no bojo da criação poética [Ibid:209], revelando-se uma operação análoga àquela ação pendular entre intertextualidade crítica e poética, anteriormente mencionada. Além disso, a Tradução Intersemiótica promove um trânsito intertextual de uma hibridação de sistemas a uma hibridação de poéticas históricas (fenômeno também observável na Intertextualidade).

Em suma, a hibridação por tradução intersemiótica produz um cruzamento que sugere uma poética capaz de refletir e atuar sobre as poéticas como hibridação intersemiótica. De um lado, operando entre as formas artísticas e as poéticas históricas, o tradutor intersemiótico hibrida sistemas; de outro, operando em diferentes gradações entre sua formatividade e a dos autores das obras originais, o tradutor (conscientemente ou não) introduz também elementos de uma hibridação de poéticas pessoais, cristalizando em sua tradução uma síntese interformativa.

\section{Hibridação interformativa}

“O operar da pessoa é plasmador de formas”. (Luigi Pareyson)

A hibridação interformativa propõe uma consciência de historicidade das Poéticas, cujos programas artísticos circunscrevem-se em âmbito histórico e em âmbito pessoal - ambos absorvidos por em sua praxis artística.

Cumpre distinguir duas modalidades de poéticas: 1) no âmbito das poéticas históricas, os "ismos", i.e. os movimentos artísticos aos quais os artistas estão inseridos; e 2) no âmbito das poéticas pessoais, incluindo tanto os programas individuais especificamente ligados à criação dos artistas como também ligados ao fazer genérico de toda pessoa.

No âmbito das poéticas históricas, vemos essas poéticas se multiplicarem em movimentos, sucessiva e ininterruptamente, com programas e manifestos dos mais variados e díspares entre si. Daí, as grafias de Poéticas no plural, que revela a multiplicidade de ideários, em contraste com Estética no singular, coerente com sua unidade filosófico-especulativa e teorética [PAREYSON,1993:297-306]. Na medida em que correspondam ao espírito ou ao ideal de um momento artístico ou histórico, essas Poéticas transformam-se em objetos de releitura por operações intertextuais e tradutoras; são rediscutidas, reabilitadas, recriadas - ou revisitadas pelas poéticas dos artistas atuais.

Como vimos, as misturas entre diferentes movimentos artísticos que presenciamos hoje - entre arte concreta, conceitual, construtiva e as artes de participação - estabelecem diálogos e aproximações entre os diferentes programas artísticos históricos, seus textos e sistemas semióticos, reelaborando-os e, prospectivamente, revalidando-os face ao pensamento artístico contemporâneo (e aos novos avanços tecnológicos) através de hibridações que envolvem as linguagens e os próprios sistemas sígnicos, acarretando predominantemente processos de hibridação intertextual-semiótica .

Já no âmbito das poéticas pessoais envolvidas em processos híbridos, opera-se uma hibridação interformativa que se configura predominantemente "sob o signo da formatividade" [Ibid:32] que pode se estender desde a produção da obra (eixo da pessoa do artista) até a sua recepção (eixo da pessoa do interator).

No eixo da produção, considero a possibilidade híbrida nas afinidades e filiações artísticas, responsáveis pelas influências e diálogos entre artistas, mestres e discípulos. Recordo que sempre haverá elementos de hibridação intertextual-semiótica, advindos da poética histórica à qual esse artista vincula sua produção individual, mas cumpre salientar que na hibridação de poéticas pessoais predomina uma hibridação entre 
formatividades, estas compreendidas enquanto estilo do artista no modo único e irrepetível de seu fazer que se integra à obra enquanto forma [Ibid:32].

Essa modalidade de hibridação interformativa é observável também em co-autorias e criações a quatro mãos, criações em grupo ou coletivas, nas quais as formatividades dos autores hibridam-se internamente à criação artística, em diálogos e embates, consensuais ou não, na busca do completamento da obra numa ação compartilhada.

Uma variante de hibridações interformativas encontra-se nas criações "paradigmáticas", na acepção de Moles, nas quais o artista introjeta e re-elabora o modus operandi ou a poética de outros artistas, em cruzamentos inéditos de linguagens. Conforme Moles, o método criativo paradigmático consiste em apreender o paradigma da criação, a linguagem e o modo de fazer de outrem e reproduzi-lo assumidamente como um procedimento poético, recriando o estilo por uma questão de afinidade eletiva ou com finalidades objetivas como, por exemplo, completar obras inacabadas, produzindo o "simulacro de um estilo, que pode ser o 'Cantus Firmus' proposto por Fucks, a sinfonia proposta por Beethoven ou a abstração geométrica proposta por Vasarely” [MOLES,1981:101]. Nesse método paradigmático eu incluo também as criações "à maneira de..." por compreendê-las como hibridações de Poéticas que envolvem hibridações interformativas. Vale mencionar aqui uma significativa interformatividade que identifico nos quatro poemas de Manuel Bandeira que compõem o conjunto "À maneira de..." nos quais o poeta simula a escrita de outros poetas como Alberto de Oliveira, Olegário Mariano, Augusto Frederico Schmidt e E. E. Cummings [BANDEIRA,991:339-342]. Esse procedimento é análogo também aos "Murilogramas", de Murilo Mendes, que integram "Convergências", livro no qual o poeta absorve a dicção de outros autores como Cesário Verde, Cecília Meireles, Souzândrade, Mário Pedrosa, Kafka etc. Nesses casos, o processo também mobiliza traduções intersemióticas.

No eixo da recepção, atribuo essa modalidade de hibridação interformativa também ao processo de interação do público com a obra, que absorve o "caráter pessoal, e portanto expressivo e formativo do operar humano" (13) reconhecível na pessoa do espectador - e, a meu ver, extensivo à sua condição de interator nas mídias digitais. $\mathrm{Na}$ arte interativa, "o ato fundamental da recepção da obra torna-se a operação", que, numa abertura de terceiro grau (14), confere ao espectador um novo estatuto na relação autor/obra/recepção.

O novo papel do espectador encontra sua expressão no neologismo spect-acteur [WEISSBERG,1999] em que "ator" refere-se diretamente à noção de ato, no sentido de uma ação — quase gestual —, por oposição à apreciação mental. Para o autor do neologismo, o hífen entre os termos é essencial, na medida em que associa a função perceptiva "spect" (ver) ao completamento do gesto daquele que atua sobre a obra. A meu ver, nesse sentido, o público - transformado em spect-acteur ou interator - opera uma hibridação poética em que sua formatividade é inserida no corpo da obra ou a impregna, pelo modo como a conduz ou a executa.

Nesse contexto, "a obra não é mais fruto exclusivo da autoridade do artista" [COUCHOT in LEÃO,2002:104], na medida em que o interator pode afetar o fluxo, alterar a estrutura ou imergir no ambiente da obra, envolvendo-se diretamente em atos de transformação e criação [POPPER, 1993,172]. Esse novo status implica num compromisso efetivo do espectador - não apenas de seu olhar [PLAZA,2000] mas de seu ato, numa conversão de estética em poética - aisthesis em poiesis [JAUSS,1978,123-157], num operar "plasmador de formas" [PAREYSON,1993:177] que favorece uma hibridação entre as poéticas do artista e dos interatores, trazendo as hibridações interformativas mencionadas no âmbito da produção para a recepção, na qual a co-autoria artista/público é mediada por um sistema inteligente. 
De modo permanente ou efêmero, o interator hibrida uma forma que é sua, afetando o campo de interpretabilidades (que se amplia com novos conteúdos e experiências) bem como a sintaxe e estrutura da obra, embutindo nela sua expressão, suas referências, seu gosto e seu tempo, traduzindo elementos intertextuais e semióticos próprios - ou já repertoriados do sistema cultural e artístico - envolvendo secundariamente uma hibridação intertextual-semiótica. $\mathrm{O}$ público, ainda que à distância, efetivamente hibrida-se na obra em tempo real na imediaticidade do feed-back. Experiencia-se uma situação em que é possível ao interator fruir sua própria formatividade contida no teor ou no ato (movimento, ritmo, pausas, tempo) de sua interação, representada pelas diferentes aparições, desdobramentos e significações da obra. Interessa-me, sobretudo, o fato de o público fruir o próprio processo de hibridação interformativa em curso (15), numa síntese entre o seu modo de ser único e irrepetível e o modo irrepetível e único do outro com quem interage (o artista ou outro interator). E, no caso das interações cumulativas, interessa-me o lançar a obra e com ela lançar-se prospectivamente à interação com um público futuro.

Assim, denomino de hibridações interformativas às operações de hibridação de poéticas que proporcionam uma dinâmica criativa entre estilos distintos e que demandam uma criação-síntese entreformatividades. Numa interformatividade de modus operandi, as hibridações de poéticas mobilizam relações artista/artista, artista/público, público/artista, público/público, promovendo encontros inusitados cuja somatória expande o repertório de signos e edifica uma poiesis enquanto lógica, ética e estética aberta a todos.

\section{Considerações finais}

“artista é mônada arte é díada público é tríada”. (Julio Plaza)

As operações de hibridação de meios, sistemas e poéticas, que se processam internamente à criação, interpenetram-se mútua e incessantemente.

No que tange às hibridações de meios, com predominância da hibridação intersensorial, observa-se que à contemporização dos diferentes meios produtivos embutidos nas imagens digitais corresponde também a contemporização dos sentidos privilegiados por esses múltiplos meios que, amalgamados, hibridam simultaneamente informação verbal, sonora, visual, tátil, cinética etc. Esse aspecto dúctil sugere um ambiente em hibridez por excelência no meio digital, revelando uma extraordinária permeabilidade de camadas de hibridações que absorvem também uma ampla gama de sistemas e poéticas.

Relativamente aos sistemas, as hibridações intertextual-semióticas viabilizam as relações intersígnicas entre formas de arte ou aquelas decorrentes das passagens de um sistema a outro. Essas hibridações produzem rupturas entre as artes, produzindo obras de complexa categorização em termos de área de conhecimento, gênero, estilo etc. Nessas matrizes híbridas, o signo estético é recriado, sintática e semanticamente, em formas análogas porém inéditas - sendo que o inevitável cruzamento de estilos dos autores envolvidos enceta aí uma hibridação de poéticas.

E nas hibridações de poéticas visualizo o paradoxo dessas interformatividades operando como influências e/ou afinidades artísticas que definem uma linhagem entre poéticas afins ao mesmo tempo em que as diferencia profundamente em suas singularidades. De outro lado, no processo criativo, reconheço o engendramento de múltiplas formatividades no enfrentamento e conjugação das poéticas de criadores, cocriadores, cooperadores, colaboradores, tradutores, autores, co-autores, em criações individuais, coletivas, grupais e em equipe. E destaco, ainda, na recepção da obra interativa, o acréscimo constante de interações que inscreve a obra num ininterrupto work in progress de ação-pensamento que é forma disponível em mutação - residindo aí uma especificidade da hibridação digital. 
Sem incorrer em categorizações rígidas, essas formulações foram apresentadas a partir do reconhecimento de suas predominâncias. É de fundamental importância ressaltar que essa classificação é de caráter inclusivo e expansivo, uma vez que, nessa imbricada teia de hibridações, as modalidades descritas deslizam-se umas sobre as outras, apropriam-se, mesclam-se - o que denota fidelidade a um princípio fundamental desejável em uma estética de misturas: a dissolução de fronteiras para o livre trânsito e interpenetrabilidade dos signos.

A criação artística contemporânea, em sua dimensão poético-política, absorve livremente essas transhibridações de meios, sistemas e poéticas; e, não raro, na unidade totalizadora da obra final, instaura-se essa imbricada interrelação de hibridações. Tal fenômeno inviabiliza uma escrita de metalinguagem com o emprego de uma metodologia classificatória rígida - sob o risco de se estabelecer uma linha demarcatória ou uma "estética de fronteiras", em oposição ao que o projeto artístico se propõe, "uma estética de misturas" (16), fundada em processos híbridos e homens inovadores em sua hibridez.

À guisa de conclusão, vale reiterar que não basta que as operações e mídias híbridas configurem um campo fértil para hibridações se o artista não for igualmente híbrido para implementá-las bem, tornandoas de fato operantes (17). Assim, podemos situar no artista, em cujo estilo já se manifesta uma predisposição para essas escolhas artísticas, a unidade inaugural que as sintetiza. Portanto, é na síntese mesma dessas hibridações, no modo próprio com que o artista as propõe, orquestra e reelabora, que podemos apreender o caráter inovador e inédito, único e irrepetível, de uma poética híbrida.

\section{Bibliografia:}

ARNHEIM, Rudolf. Intuição e Intelecto na Arte. SP: Martins Fontes, 1989.

APOLLINAIRE, Guillaume. Calligrammes.Paris: Gallimard, Collection Poèsie, 1925.

ARAÚJO, Ricardo. Poesia Visual - Vídeo Poesia. SP: Perspectiva, Debates nr.275, 1999.

BAKHTIN, Mikhail. Marxismo e Filosofia da Linguagem. SP: Hucitec, 6a ed., 1992.

Questões de Literatura e de Estética. SP: Ed.Unesp, 4a ed., 1998.

BANDEIRA, Manuel. Estrela da Vida Inteira. RJ: José Olympio, $19^{\text {a }}$ ed, 1991

BENJAMIN, Walter. Obras Escolhidas (VOL.I) SP: Brasiliense, 3a ed., 1987.

BENSE, Max. Pequena Estética. SP: Perspectiva, Col. Debates nr.30, 2a ed., 1975.

CAMPOS, Augusto et alli. Teoria da Poesia Concreta. SP: Livraria 2 Cidades, $2^{\text {a }}$ ed, 1975.

CAMPOS, Haroldo (org). Ideograma—Lógica, Poesia, Linguagem. SP: EDUSP, 3a ed, 1984.

. A Arte no Horizonte do Provável. SP: Perspectiva, Debates nr.16, 4a ed, 1977.

. Metalinguagem. Petrópolis: Vozes,1967.

COUCHOT, Edmond. "Hybridations" in THÉOFILAKIS, Élie. (org.) Modernes, et Après? "Les 
Immatériaux”. Paris, Éditions Autrement, 1985.

- "Da Representação à Simulação: Evolução das Técnicas e das Artes da Figuração". In: PARENTE, André (org.) Imagem-Máquina: A Era das Tecnologias do Virtual, RJ: Ed. 34, 1993.

. "O Tempo Real nos Dispositivos Artísticos" in: LEÃO, Lúcia (org.) Interlab: Labirinto do Pensamento Contemporâneo. SP: Fapesp/Iluminuras, 2002.

. A Tecnologia na Arte da Fotografia à Realidade Virtual. Porto Alegre: Ed. UFRGS, 2003.

. "Boïts Noires" in KLONARIS et THOMADAKI (org) Technologies et Imaginaires - Art

Cinéma Art Vidéo Art Ordinateur. Paris: Dis Voir, 1990.

ECO, Umberto. Obra Aberta. SP: Perspectiva, Debates nr. 4, 2a ed, 1988.

JAKOBSON, Roman. Lingüística e Comunicação. SP: Cultrix, 13a ed, 1988.

JAUSS, Hans Robert. "O Prazer Estético e as Experiências Fundamentais da Poiesis, Aisthesis e Katharsis" in: LIMA, Luiz Costa (org). A Literatura e o Leitor. RJ: Paz e Terra, 1999.

KANT, Emmanuel. Critique de la Faculte de Juger.Paris: Philosophique J.Vrin. 6a ed., 1984.

KRISTEVA, Julia. La Révolution du langage poétique. Seuil, 1974 In: Intertextualidades. Coimbra: Livraria Almedina, Poétique 27, 1979.

MCLUHAN, Marshall. Understanding Media- The Extension of Man . copyright 1964, London, England, Cambridge, Massachusetts, The Mit Press, 1994.

Cultrix Ltda, 1969.

. Os Meios de Comunicação como Extensões do Homem (Understanding Media) . SP: Ed.

MOLES, Abraham Antoine. A Criação Científica. SP: Perspectiva, 1981.

PAREYSON, Luigi. Estética - Teoria da Formatividade. Petrópolis, RJ: Vozes, 1993 , Os Problemas da Estética. SP: Martins Fontes, 1997

PAZ, Octavio. "Traducción: Literatura e Literalidad” in: Cuadernos Marginales 18. Barcelona: Tusquets, 1971.

PEIRCE, Charles Sanders. Semiótica. SP: Perspectiva, Col. Estudos nr. 46, 1977.

PERRONE-MOYSÉS, Leyla. “A Intertextualidade Crítica” in Intertextualidades. Coimbra: Livraria Almedina, Poétique nr. 27,1979.

PIERRE, Lévy. Cibercultura. SP: Editora 34, 2a ed. 2000.

PIGNATARI, Décio. Informação Linguagem Comunicação. SP: Cultrix, 1980. 
. Semiótica \& Literatura. SP: Cortez \& Moraes, 2a ed, 1979.

. Contracomunicação. SP: Perspectiva, Col. Debates nr.44, 2a ed, 1973.

PLAZA, Julio. Tradução Intersemiótica. SP: Perspectiva, Col. Estudos 93, 1987.

. A Imagem Digital. SP: Livre-Docência, ECA/USP, 1991.

Arte e Interatividade: autor-obra-recepção. Revista Ars ECA/USP. São Paulo, nr. 2, 2003, pp 8-

29.

. TAVARES, M. Processos Criativos com os Meios Eletrônicos. SP: Hucitec. 1998.

POPPER, Frank. Art of the Electronic Age. Thames and Hudson Ltd., 1993.

SAUSSURE, Ferdinand de. Curso de Lingüística Geral. Col. Un. Moderna, 18, 4a ed., 1971.

VALENTE, Agnus. ÚTERO portanto COSMOS: Hibridações de Meios, Sistemas e Poéticas de um SkyArt Interativo. São Paulo: Escola de Comunicações e Artes da Universidade de São Paulo - ECA/USP, 2008. 237 p. Tese de Doutorado em Artes Visuais.

Parabola-Imago: Transmutações Criativas entre o Verbal e o Visual. São Paulo: Escola de Comunicações e Artes da Universidade de São Paulo - ECA/USP, 2002. Dissertação de Mestrado em Artes Visuais.

VAUDAY, Patrick. La matière de Images. L'Harmattann, 2001.

WEISSBERG, Jean-Louis. Présences à Distance. 1999. < http://hypermedia.univparis8.fr/Weissberg/presence >

. "Simuler-Interagir-S'Hybrider=le Sujet rentre sur scène" in THÉOFILAKIS, Élie. (org) Modernes, et Après? “Les Immatériaux”. Paris: Éditions Autrement, 1985.

\section{Notas:}

As reflexões constantes neste artigo já foram publicadas com diferentes versões anteriormente, em outros artigos: mais recentemente no $8^{\circ}$ Encontro Internacional de Arte e Tecnologia (\#8.ART), realizado pelo Programa de Pós-Graduação em Arte do Instituto de Artes da UnB - Universidade de Brasília, focando especificamente nas hibridações interformativas e, em breve, será publicado artigo contendo a versão completa de hibridações no anual do XVIII Congresso da ANPAP 2009.

(1) Estas contribuições são pensadas tanto no contexto abrangente dos estudos de Moles em A Criação Científica, onde o autor apresenta uma abordagem ampla da metodologia da criação científica aplicável também às artes, como no contexto de Processos Criativos com os Meios Eletrônicos: Poéticas Digitais, de Plaza \& Tavares, que aborda a criação artística numa perspectiva interdisciplinar Arte\&Ciência, na especificidade dos meios eletrônicos.

(2) O meu critério aqui é análogo ao de "função predominante" aplicado por Jakobson [1988:123] ao 
estudo das funções da linguagem.

(3) Refiro-me à Teoria da Poesia Concreta [CAMPOS et alli,1975]. Mais recentemente, o poeta comenta em seu artigo "Do Tipograma ao Videograma" que "a articulação dos procedimentos de alta definição cinética dos supercomputadores gráficos com os recursos sonoros de um estúdio também computadorizado (gravação em vários canais, decomposição fônica, montagens e superposições, ecoizações e outros efeitos) permite que quase se chegue de modo mais cabal à materialização das estruturas verbivocovisuais prenunciadas pela Poesia Concreta" [CAMPOS in ARAÚJO,1999:168-169].

(4) Bense promove uma ampliação do termo às Artes Visuais com este comentário: "gostaria de sugerir que o conceito peinture, veiculado de longa data (e que, ademais, tem ao mesmo tempo natureza geral, abstrata e material), na teoria geral da imagem corresponderia àquilo que, na teoria geral do texto, se admite como texto" [1975:179].

(5) Julia Kristeva parte do pressuposto de que "qualquer texto se constrói como um mosaico de citações e é absorção e transformação dum outro texto". Entendendo "texto" como um "sistema de signos", Kristeva ampliou o termo "intertextualidade", que considerava restritivo, estendendo o conceito também às linguagens não-verbais.

(6) Para Saussure, a imagem acústica "não é o som material, puramente físico, mas a marca psíquica desse som, a sua representação fornecida pelo testemunho dos sentidos; é sensorial e se, por vezes lhe chamamos 'material' é neste sentido e por oposição ao outro termo da associação, o conceito, geralmente mais abstracto", [SAUSSURE,1978:122].

(7) Esta é a grafia com que Jakobson apresentou o termo em sua tipologia das traduções, definindo a tradução "intralingual”; tradução "interlingual" e a tradução "inter-semiótica" [JAKOBSON,1988:64-65].

(8) Retroativamente, este conceito aqui formulado atende às operações realizadas no meu projeto criativo de Mestrado PARABOLA-IMAGO: Transmutações Criativas entre o Verbal e o Visual, realizado entre 1997 e 2002, no programa de Pós-Graduação ECA/USP.

(9) Refiro-me às funções da Linguagem [JAKOBSON,1988:130]. Conforme Haroldo de Campos, o fato de se oporem não impede que a função poética da linguagem atue concomitantemente à função de metalinguagem, com as quais, por exemplo, o poeta reflete sensivelmente sobre o ato de escrever um poema. [1977:141].

(10) Receando a banalização do termo intertextualidade, Julia Kristeva propôs o termo-substituto 'transposição'; para ela 'O termo 'intertextualidade' designa essa transposição de um (ou vários) sistema(s) de signos noutro, mas como este termo foi freqüentemente tomado na acepção banal de 'crítica das fontes' dum texto, nós preferimo-lhe um outro: transposição, que tem a vantagem de precisar que a passagem dum a outro sistema significativo exige uma nova articulação do tético - da posicionalidade enunciativa e denotativa." [KRISTEVA, 1974:60].

(11) A tradução indicial estará determinada pelo seu signo antecedente; contudo esta relação será de causa-efeito (caso da tradução de um signo para outro meio) ou terá uma relação de contigüidade por referência que se resolverá na sua singularidade, pois acentuará os caracteres físicos do meio que acolhe o signo. Contudo, ela será interpretada através da experiência concreta. A tradução será neste caso uma transposição." [PLAZA,1987:93].

(12) Na tradução indicial, “O objeto imediato do original é apropriado e transladado para um outro meio. 
Nesta mudança, tem-se transformação de qualidade do Objeto Imediato, pois o novo meio semantiza a informação que veicula." [PLAZA,1987:91-92].

(13) Esta reflexão encontra-se no Cap.V, "Interpretação e Contemplação", a respeito da formatividade ligada ao papel do espectador em sua relação com a obra [PAREYSON,1993,176].

(14) Tendo a Obra Aberta na base das Poéticas Participativas (abertura segundo grau), Plaza introduz o terceiro grau, concernente a uma expansão para as Poéticas Interativas, face às mídias digitais [2000:10].

(15) Nas exibições de ÚTERO portanto COSMOS, em ambiente físico, pudemos observar os interatores em ação, exercendo simultaneamente o papel de espectadores de sua própria formatividade em curso na obra interativa.

(16) A expressão "estética de fronteiras" e "estética de misturas" são empregadas aqui na mesma acepção aplicada respectivamente a Lessing e Diderot por Vauday [2001, 189-192].

(17) Paráfrase desta afirmação de Edmond Couchot: "Pour ces techniques hybrides, il faut des artistes également hybrides qui soient capables de bien les maïtriser et les combiner", cuja tradução livre transponho aqui (t.a.): "Para essas técnicas híbridas, são necessários artistas igualmente híbridos que sejam capazes de bem orquestrá-las e combiná-las" [COUCHOT in:KLONARIS;THOMADAKI,1990:51].

\section{Mini Currículo :}

Artista híbrido. Doutor em Artes pela Escola de Comunicações e Artes ECA/USP com a tese ÚTERO portanto COSMOS: Hibridações de Meios, Sistemas e Poéticas de um Sky-Art Interativo (2008), com orientação de Carmela Gross; Mestre em Artes pela ECA/USP com a dissertação PARABOLA-IMAGO: Transmutações Criativas entre o Verbal e o Visual (2002), com Bolsa FAPESP e orientação de Julio Plaza; Docente no Departamento de Artes Visuais do Instituto de Artes IA/UNESP; organizador da Revista HIBRIDA Eletrônica; e Pesquisador do Grupo de Pesquisa Poéticas Digitais, coordenado por Gilbertto Prado-ECA/USP.

Site c1998-2009 www.agnusvalente.com. 